\title{
The Generation and Application of New Business Models in Cross-cultural Management ---based on the cases of Chinese innovative Internet business model Xi JIANG ${ }^{1, a}$, Bo XU ${ }^{2, b}$
${ }^{1}$ Management School Shanghai University of International Business and Economics, Shanghai, China
${ }^{2}$ Management School Shanghai University of International Business and Economics, Shanghai, China ajiangxi-219@163.com, brianxubo@163.com
}

Keywords: business models, cross-cultural management, PEST

\begin{abstract}
We analyze the different influences of external environment (politics, economics, soci-culture and technology) in the generation and application of new business models. The approach of this paper is case study of Chinese innovative business models which are based on the Internet technology. Then the paper will, from the view of cross-cultural management, focuses on the four solutions (transplantation, adjustment, remodeling, abandon) of generation and application of new business models.
\end{abstract}

\section{Introduction}

It is quite advisable to overcome development bottleneck and improve core competitiveness through business model innovation. After encountering the development bottlenecks, approximately two-third of those companies faced bankruptcy or acquisition. Only less than $10 \%$ of the enterprises recovered and seized a sustainable competitive advantage through building business mode. [1]

Most of the new business models in China are learned from overseas mature business models. The markets in Europe and the United States are more developed. However, there are some differences in consumer spending habits and consumer preferences between the local market and western market. Especially on the cultural level, there are needs to make adjustment!

This article will explore several types of new business models--- P2P network credit, B2C Internet shopping / traveling. P2P (peer to peer) network lending business had been popular in China. At the end of 2011, there were less than ten companies are actually operating healthily. B2C online shopping / traveling agencies, such as Taobao, Ctrip, Yixin Group are outstanding at operating and building new business model; enterprises such as PPG, Chang Xiang Network are unfortunately failed. It is obvious that companies with the same innovative business model may get opposite results, due to various operational mistakes.

\section{Literature Review}

Clayton Christensen published one article in the Harvard Business Review --- What is the business model, in which he described the basic concepts of business model. Christensen also divided business model into four key elements: customer value proposition, profit model, key resources and key processes. Gray Hamel proposed the four dimensions of the business model --- customer interface, core strategy, strategic resources and value network. [2]Morris believes that the change of business model is progressing from the foundation level to the proprietary layer and rules level.[3]

Cross-cultural management is an emerging discipline gradually formed and developed in the late 1970 s in the United States. Its research field is to how overcome the heterogeneity of cultural conflict, and how to conduct effective management in the context of different cultures. For reasons of the culture differences, Hofstede believed that culture is not an individual characteristic but a psychological process shared by people who have the same education and life experience. [4] For the 
impact of cultural differences on business, researchers have concluded that personal behavior, interpersonal relationship, and communication affect the organization. [5]

In summary, the current research on business model are mostly concentrated in the direction of change as well as the level, they rarely involves obstacles and solutions of innovative business models in the local market and, and not to mention the analysis of operation from the point of view of cross-cultural management.

\section{The Challenges of Business Model Innovation --- Based on PEST Analysis}

PEST (Political Factors, Economic Factors, Socio-cultural Factors, Technological Factors), as the classic macro environment analysis, has been used by numbers of enterprises for strategic background analysis. When analyzing the obstacles of new business models, PEST analysis can be conducted by horizontal comparison of the four factors, find the real obstacles of innovative business models.

In general, innovative business models based on network technology suffer fewer influences from the political, economic and technological environment. For a new business model, its existence must cater to the needs of the market, the government's policy guidelines should be positive. At the same time, the emergence of any kind of innovative business practices is always with the uncertainty and unpredictability. Therefore, most of the laws and regulations are conservative.

In view of the economic environment, the Chinese and foreign consumers have similar consumer spending power and desire, taking into account the speed of China's economic development, the similarity of market environment will become increasingly high.

External technology environment in business model innovation generally will not encounter greater obstacles. The technological environment is objective, the introduction and development of hardware facilities are processes of purchasing and learning.

Clearly, there are significant differences in culture (society), due to the different history, cultural values, and consumer attitudes. This means that the business model fully replicated from the U.S. and European markets cannot be entirely agreed with the domestic consumers. For example, barter is very popular in Europe and USA. However, Chinese people have the strong concept of ownership, and they are reluctant to exchange items.

In some aspects of Chinese-Western culture, such as values, interpersonal relationship, the differences are significant. Due to the country's historical lineage, there are also differences in recognizing business model. According to the characteristics of the local market, in the view of cross-cultural management, we propose four solutions for innovative business models --transplantation, adjustment, remodeling, abandon. The four methods of analysis will commence in the next part of this article.

\section{Cross-cultural Management of Business Model Innavation}

The below five innovative business models (Table 1) are based on the network technology. We, referring to Hofstede's culture model of five-dimension, analyze these five types of innovative business models.

Table 1, Culture Analysis of Five Business Model

\begin{tabular}{|l|l|l|l|l|l|l|}
\hline & $\begin{array}{l}\text { five- } \\
\text { dimension } \\
\text { business } \\
\text { model }\end{array}$ & PDI & UAI & IDV & LTO & MAS \\
\hline $\begin{array}{l}\text { National } \\
\text { Popularizati } \\
\text { on }\end{array}$ & $\begin{array}{l}\text { P2P } \\
\text { network } \\
\text { borrowing }\end{array}$ & $\begin{array}{l}\text { low } \\
\text { PDI }\end{array}$ & high UAI & collectivism & short-term & masculinity \\
\cline { 2 - 8 } & B2C & low & high UAI & collectivism & --- & femininity \\
\hline
\end{tabular}




\begin{tabular}{|l|l|l|l|l|l|l|}
\hline & $\begin{array}{l}\text { e-commerc } \\
\text { e }\end{array}$ & PDI & & & & \\
\hline \multirow{2}{*}{$\begin{array}{l}\text { Local } \\
\text { popularity }\end{array}$} & Internet & low & low UAI & individualism & short-term & --- \\
\cline { 2 - 7 } & Internet & low & less higher & individualism & short-term & femininity \\
& register & PDI & UAI & & & \\
\hline emerging & Coach & low & extremely & collectivism & short-term & femininity \\
& Surfing & PDI & high UAI & & & \\
\hline
\end{tabular}

Given the fact of culture difference, Chinese consumers have different understanding of the above five models. In the localized implementation phase, we propose the following four operations: transplantation, adjustment, remodeling, abandon.

TransplantationThe customer service design under different cultural backgrounds can be learned from each other, and even directly transplanted.

Let us look at the case of P2P network--- a commercial platform. The nature of their business is a platform of exchanging information, and an informal financial institutions. As a result, companies cannot guarantee the authenticity of customers' and the on time repayment. The earliest foreign P2P business --- British Zopa Company divided credit into four grades, loaner chose the debtor based on the amount of idle funds, risk tolerance status. The higher the credit rating, the lower the cost of borrowed funds interest rate. When P2P enter China, almost all domestic P2P lending company set up both lenders and borrowers credit rating system.

When it comes to risk aversion, the Chinese enterprises also directly draw lessons from foreign companies. The platform require the creditors agree to lend funds to the 50 different lenders to realize the risks of fully dispersed. For funds borrowers, monthly interest payments are required. P2P companies will participate in funds registration, identification, credit rating, the contract development, and recovering debts. All users of the platform will be provided third-party interest payment.

The same phenomenon also appears in the $\mathrm{B} 2 \mathrm{C}$ business areas, in order to prevent the sellers do not ship after customers' payments, EBAY firstly launched third-party payment, resolving customer payment uncertainty concerns. Similarly, Taobao also took the lead in establishing Alipay third-party platform to protect customers' payment security.

Adjustment.Influenced by different cultural values, consumers are sometimes biased in understanding in business philosophy. But if the bias does not touch on the moral bottom line operators, enterprises can adjust moderately.

In foreign countries, almost all of the profit model of P2P enterprises are charging intermediary fees (a certain percentage each transaction amount). But the charging mode does not apply in China. China's network borrowings oriented groups are broad --- not only the working-class, but the farmers who have difficulties in financing, SMEs as well as college students. Also China's Internet lending market is crowded. Therefore, customers hope to compare the cost of all the borrowing platform.

Recognizing this problem, domestic lending company introduced a flexible, diverse pricing policy. Yixin Group achieves profitability by third-party intermediary fees, the percentage depends on the borrower's credit quality. Haha Loan is an enterprise loans for students and they charge through three channels: third-party platform transfer costs (fixed to 1\%), transaction service fees (3\%), late charges (7\%).Micro-credit Network requires customers to pay membership fees (RMB120/ year) + management fees (a certain percentage of the principal amount) + margin (it will thaw after paying off loans). Obviously, for the business model with a certain risk, companies are willing to achieve profit through a variety of pricing.

Remodeling.With the development of China's market-oriented, consumer culture blank is filled. Consumer culture might not exist before and filling consumer culture is a process of building 
consumer attitudes. Corporate needs to educate the customers, and reshape the image of the business model.

We will analyze the problem through a negative example. Changxiang Network was as famous as Ctrip, whose target clients were SMEs. It not only helped corporate booking air tickets and hotel, but also got through the payment and procurement bottlenecks, making the mission personnel no longer directly contact with the cash and invoices. Moreover, Changxiang operate monthly billing system with Hotel and enterprise customer, the travel expenses of the enterprise can be advanced paid by Chang Xiang. But Changxiang Network did not so well in customer education. Its customers were still confused for month-end funds and non-cash payment mode. In late period of operation, the customer does not timely pay back to Changxiang, hotel partners declined sharply, eventually leading to Changxiang funds strand breaks.

In July 2012, Zhejiang court launched online judicial network auction for the first time. It is a good way to eliminate court corruption as long as the process is transparent. However, this auction has been resisted by traditional auction industry. They believed that such actions "dove over the magpie's nest." Because of this misunderstanding, this auction does not promote in the country. If customers are well educated, aware of the meaning and scope of online auctions and auction process is made clear, online auction will certainly be popular across the country after remodeling.

Abandon.Some aspects of Chinese and foreign cultures are irreconcilable, the commercial behavior represented by the culture should be completely abandoned. Take the Network borrowing credit identification as an example, there are national credit system in westen world. When investigating credit identification, the platform can transfer from credit data, then analyze he customer's credit rating. In China, in the short term we are unable to establish a secure and reliable universal credit system. If continue to follow the method of identification of foreign credit, the P2Pcompanies will undoubtedly cause huge cost in time and money.

The domestic P2P enterprise completely abandoned the practice of the foreign credit rating. Instead, they require customers to submit identity material. The basic materials including ID card, residence booklet, certificate of work, bank certificates of deposit or phone bill. The staff will audit of the material, and confirm the material by referring to the public security bureau. For any user who can provide additional materials will be appropriate to improve their credit rating. Overall, Chinese P2P platform identify the identity authenticity of applicants through basic material, and rate credit level by auditing additional material.

\section{Acknowledgements}

This study is supported by Humanities and Social Science Research Program Foundation of Ministry of Education of China (No.11YJA630162), The 2012 First Batch of Major Projects of the National Social Science Fund (No. 12\&ZD024), Innovation Program of Shanghai Municipal Education Commission (No.12ZS172), The 085 Project.

\section{References}

[1] M.W. Johnson, C. M. Christensen and H. Kagermann: Reinventing Your Business Model (Harvard Business Review, USA 2011).

[2] G. Hamel, in: Lead the Revolution, edited by Harvard Business School Press, Boston, Massachusetts (2000), in press.

[3] M. Morris: The Entrepreneurs' Business Model: Toward a Unified Perspective (Journal of Business Research, USA 2003).

[4] G. Hofstede. The Cultural Relativity of Organizational Practices and Theories (Journal of International Business Studies, UK 1983).

[5] H. Schwartz, S. Davis: Matching Corporate Culture and Business Strategies (Organizational Dynamics, USA 1992). 